\title{
ASSESSMENT OF THE TRENDS OF GREENHOUSE GAS EMISSION IN ETHIOPIA
}

\author{
Besfat D. Engdaw ${ }^{1 *}$ \\ 'Bahir Dar University, Tana Sub-City, Bahir Dar, 6000, 79, Ethiopia \\ *Corresponding author: besfloved@gmail.com \\ Received: November $6^{\text {th }}, 2018$ / Accepted: May 10 ${ }^{\text {th }}, 2020$ / Published: July 1 15t, 2020 \\ https://DOI-10.24057/2071-9388-2018-61
}

\begin{abstract}
This paper assesses the trends of greenhouse gas emissions in Ethiopia. To assess the trends of greenhouse gas emissions, the paper uses quantitative data ranging from 1990-2013. This data is ascertained from United Nations Framework Convention on Climate Change Data interface. The Paper analyzed these data using descriptive methods of data analysis. Accordingly, the paper revealed that Ethiopia has shown increasing trends of emission in most sectors, except land use-land use change, and forestry. Having an average emission of $50739.73 \mathrm{GgCO}_{2 \mathrm{e}^{\prime}}$ land use-land use change, and forestry is the largest sector that contributes to greenhouse gas emissions in Ethiopia. The agricultural sector played the second largest role with an average emission level of $47093.63 \mathrm{GgCO}_{2}$. Following the above two sectors, the energy sector, ranked third, has contributed an emission of $17670.13 \mathrm{GgCO}_{2}$. Other sectors like waste, industrial, and international bunkers have contributed a trivial amount to the country's greenhouse gas emissions, with average greenhouse gas emissions of 3081.21 $\mathrm{GgCO}_{2 \mathrm{e}^{\prime}} 881.21 \mathrm{GgCO}_{2 \mathrm{e}^{\prime}}$ and $458.65 \mathrm{GgCO}_{2 \mathrm{e}}$ respectively. However, the annual emissions growth rate of the bunker sector is very high accounting for $57.53 \%$. The industrial sector has shown a $20.05 \%$ average annual growth rate followed by land use- land use change and forestry with an annual emission growth rate of $19.76 \%$. The energy sector and waste sector have 9.45\% and $7.4 \%$ average annual growth rates. The agricultural sector has a $3.11 \%$ of average annual growth rate. The country has introduced different policy instruments. However, most of the policy instruments are not effective enough.
\end{abstract}

KEY WORDS: Greenhouse Gas emission, Carbon dioxide, Methane, Nitrous oxide, LULUCF

CITATION: Besfat D. Engdaw (2020). Assessment Of The Trends Of Greenhouse Gas Emission In Ethiopia. Geography, Environment, Sustainability, Vol.13, No 2, p. 135-146

https://DOI-10.24057/2071-9388-2018-61

ACKNOWLEDGMENTS: I would like to acknowledge Professor David W. Tushaus, US Ambassador's Distinguished Scholar at School of Law, Bahir Dar University and Fulbright Scholar Liaisons, for his unreserved comments, insights, and intense proofreading to further develop the manuscript. I would also like to acknowledge the anonymous reviewers for their valuable and important comments, their comments are scientifically very important to advance value of the manuscript.

Conflict of interests: The author reported that there is no conflict of interest.

\section{INTRODUCTION}

Greenhouse gases are gaseous substances that help to regulate the temperature of our planet. Without greenhouse gases, our planet would be too cold. However, rigorous recent human activity has led to an increased greenhouse gas emission in the atmosphere. This affects the natural system in which the atmosphere regulates the temperature of the earth. Due to increased greenhouse gas emissions induced by man, the planet is now getting hotter and hotter. Consequently, global warming becomes one of the major environmental challenges that the world has faced. Among the greenhouse gases, carbon dioxide, nitrous oxide, methane, and fluorinated greenhouse gases are the major ones. They have contributed more than $76 \%$ of the globally increased greenhouse effects (See 2001). The total greenhouse gas including land use-land use change and forestry increases gradually. During the 1990s, it was $22219.63 \mathrm{mt} / \mathrm{CO}_{2 .}$. However, toward the turn of 2000, the total greenhouse emission including land use-land use and forestry change was around $27205.08 \mathrm{mtco}_{2}$. In the year 2013, the total greenhouse gas emission, including LULUCF, have reduced to $18739.21 \mathrm{mt} /$ $\mathrm{CO}_{2 \mathrm{e}}$. From 1990 - 2013 the average growth of world green- house gas emissions was around 1.544\% (CAIT 2017). On the other hand, the total greenhouse emission excluding land use-land use change and forestry was around $22866.8 \mathrm{mt}-$ $\mathrm{CO}_{2 e}$. From 1990-2013 the average growth of world greenhouse gas emissions, excluding LULUCF, was around 2.05\%. This statistical data has proved that the global greenhouse gas emissions with and without LULUCF have increased on average at 1.54 and 2.05\% per year respectively (UNFCCC 2017). As a result of this, greenhouse gas emission has become a global, national and local policy issue that many countries around the world are trying to address.

Although developing countries have less contribution to global greenhouse gas emissions, they have shown increasing trends and patterns. Despite the fact that developing countries, particularly Africa, produce less anthropogenic greenhouse gas emissions, they are highly exposed and vulnerable to climate variability and climate-related events (Sarkodie and Strezov 2019). Developing countries have shown $270.66 \%$ of average growths in 2013 as compared to the 1990s net total greenhouse gas emissions. From 19902013, developing countries have an average growth rate of 65.6\% annual greenhouse gas emissions per year (UNFCCC 2017). As a part of developing countries, Sub Saharan coun- 
tries have also shown increasing trends in greenhouse gas emissions. The total greenhouse gas emission of Sub Saharan African countries was 3,867 $\mathrm{MtCO}_{2 e}$ in 1990 and reached $4542.4 \mathrm{MtCO}_{2}$ in 2010 with an average growth of $17.5 \%$ (IEA 2012). CAIT (2017) has also revealed that the region has an average growth rate of $13.3 \%$ in 2013 as compared to the 1990s. Therefore, Ethiopia is not an exception as there have been increased trends in greenhouse gas emissions.

There are several causes for greenhouse gas emissions, but the major causes are fossil fuel burning, forestry harvest and land-use change, agricultural activities and industrial processes. Sectors like agriculture, energy, wastes, bunker fuels, land-use change and forestry (LULUCF), and industries have been contributing immensely to greenhouse gas emissions. In developed countries, the energy sector (fossil fuel) and the industrial sector are the main sources of greenhouse gases. However, in developing nations, like Ethiopia, landuse change and the forestry (LULUCF) and the agricultural sector are the main sources of greenhouse gas emission. In Ethiopia, the agricultural sector and land-use change and forestry contributed a huge share for greenhouse gas emissions (FDREMoEF 2015; USAID 2015). Other sectors like manufacturing, industry, energy, and wastes have insignificant contributions to greenhouse gas emissions. However, in terms of average annual growth rates some sectors like industrial sectors and wastes, have shown despicable increments in their contribution to greenhouse gas emissions (USAID 2015).

This paper will contribute to the existing literature by analyzing the trends of greenhouse gas emissions in Ethiopia, examining the contributions of agricultural, land use-land use change and forestry, energy, industry, waste and bunkers fuel sectors in greenhouse gas emission. It depicts out the trends of greenhouse gas emissions in these sectors, and investigate the policy instruments and measures of greenhouse gas emissions in Ethiopia.

\section{MATERIALS AND METHODS}

A qualitative research methodology has been employed. The paper applied a qualitative research methodology because the prime goal of the paper, assessing the trends of greenhouse gas emissions, needs a descriptive research approach, which is purely qualitative. Moreover, making inferences, or association of variables, is not the objective of the paper. So the paper finds qualitative research methodology best addresses its objective. The paper is entirely de- pendent on secondary data, which are ascertained from the UNFCCC (United Nations Framework Convention on Climate Change). The greenhouse gas emission data from UNFCCC is supposed to be the most reliable source of data as they are directly collected from concerned countries. It draws data from annex I and non-annex I countries using consistence reporting mechanisms. This paper draws Ethiopia's 24-year data of greenhouse emissions that are already found at the UNFCCC. The paper covers data ranging from 1990-2013. The paper disregards data after 2013 due to a lack of statistical data. These quantitative data are presented using graphs, diagrams, and charts.

\section{RESULTS AND DISCUSSION}

\section{Greenhouse Gas Emissions in Ethiopia}

There has been a rising trend in aggregated national greenhouse gas emissions in Ethiopia. Estimated emissions in 2013 were about $927.46 \%$ higher than in 1990, but $29.35 \%$ and $28.86 \%$ lower than the 2000 and 2010 emission respectively. Generally, the net greenhouse gas emissions, removal with LULUCF, have increased on average 28.89\% per year from 1990-2013. However, after 2011 the net greenhouse gas emissions have shown decreasing trends as it was $192,336.5 \mathrm{GgCo}_{2 \mathrm{e}^{\prime}} 124,656.7 \mathrm{GgCo}_{2 \mathrm{e}^{\prime}}$ and $120,500.6 \mathrm{GgCo}_{2 \mathrm{e}}$ in 2011, 2012 and 2013 respectively. (Fig. 1).

Greenhouse gas emissions estimations are very important to have informed decisions about emission reduction strategies. However, it is affected by a number of uncertainties. So, it is vital to acknowledge that the greenhouse gas emission estimates have a certain level of uncertainty that needs to be taken into account. In Ethiopia, the main activity data used to build the national inventory were gathered from official annual reports produced by the government institutions. However, the data do not include metadata showing the uncertainty levels nor do they provide the statistics needed to estimate the uncertainty of the activity data they generate. Since these institutions do not calculate the uncertainties associated with the data that they submit, it is impossible to determine the uncertainty associated with emission calculations in the national inventory. Nevertheless, the uncertainty levels resulting from the use of default factors have been computed. The uncertainty assessment of the total inventory was estimated with a total inventory uncertainty of $4.2 \%$ and trend uncertainty of $27.9 \%$ (FDREMoEF 2015)

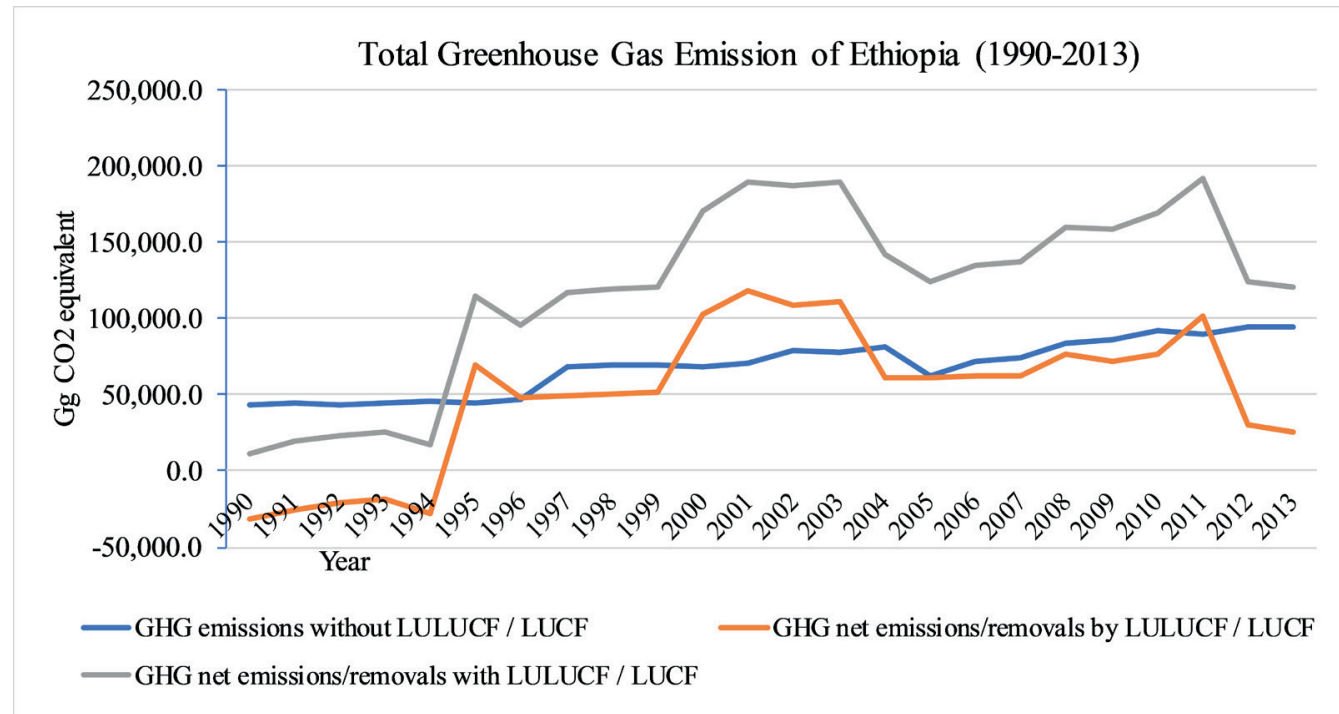

Fig. 1. Computed from UNFCCC Data Interface 


\section{Carbon dioxide}

The Intergovernmental Panel on Climate Change indicated that global warming and climate change have become the world's most critical issues in recent decades, with a significant increase in carbon dioxide emissions. Natural and human activities are the causes of $\mathrm{CO}_{2}$ emissions. However, the primary cause of $\mathrm{CO}_{2}$ emission nowadays is attributed to human activities, particularly economic activities (IPCC 2001). It has an immense contribution to world greenhouse gas emissions. Anthropogenic factors have contributed to a 9.8\% emissions growth rate from 1990-1997. This growth rate has been doubled in the subsequent years as a $20.5 \%$ growth rate was evident from 1998-2005. However, the growth rate in carbon emission has shown little decrement from 2006-2013 as it was around 16\% (CAIT 2017). This might be because of the policy measurements that were taken by the global environmental regimes.

The emission of carbon in developing countries has shown a gradual increase, though little when it is compared with the emissions of developed nations. The major sources of carbon emission in developing nations, excluding China, India, and Brazil, are related to agricultural activities and land use-land use change and forestry. In Ethiopia, like other developing nations, the major sources of carbon emissions are LULUCF and agricultural activities. The carbon emissions including/excluding LULUCF have a colossal variation. The level of carbon emission including LULUCF is higher than the level of carbon emission excluded LULUCF. Since 1990, the average carbon emission in Ethiopia, including LULUCF, has been around $55966.23 \mathrm{Ggtco}_{2 e^{\prime}}$ however, the carbon emission except LULUCF is around $5293.67 \mathrm{Ggtco}_{2 e}$. The disparity between excluding and including LULUCF emission is because the country does not produce carbon emissions from the combustion of fossil fuels. Even though the country has 320 million tons of potentially exploitable coal, it has exploited zero percent of it (FDREMoEF 2015). Except for the transport sector, Ethiopia does not produce carbon emissions as it does not generate power/energy by burning fossil fuels. Hence, most of the carbon emissions in Ethiopia are attributed to land-use change and forestry and the transport sector. According to FDREMoEF, (2015) the carbon dioxide emission from land use and land use changes in cropland and grassland contributed 92\% (cropland 59\% and grassland 33\%). Transport and the energy sector followed as the other main sources $\mathrm{CO}_{2}$ emission, which accounted for 3\% and 1\% respectively. However, looking at the average growth rate of carbon emissions, LULUCF (Land use- Land use change and forestry) included carbon emissions are greater than LULUCF excluded carbon emission as the former increased by $17.3 \%$, while the later increased with $7.5 \%$ since 1990 (Fig. 2). With all these increasing and decreasing trends of $\mathrm{CO}_{2}$ emissions, the economic activities of the country have played great roles. The $\mathrm{CO}_{2}$ emission, including LULUCF, has shown a drastic increment after 1994. This can be because of the extensive deforestations (i.e. an estimate of annual deforestation ranges from 39,000 hectares in 1990 to more than 143,000 hectares after 1994 and the percentage of forest rent to the country's GDP has also raised from $11.88 \%$ in 1990 to 22.75 in 1994), population growth and economic activities. According to World Bank (2013) the GDP per capita of the country has shown colossal variabilities from 1990-2003, with the lowest GDP per capita growth rate of $-11.893 \%$ in 1991, the time when the country had the highest reduction of $\mathrm{CO}_{2}$ emissions. However, after 2004 the country had no negative GDP per capita with the highest growth rate of $10.408 \%$ in 2004 . The $\mathrm{CO}_{2}$ emission, which has started falling from 2002-2003, has started rising again after 2004. In 1990 the carbon dioxide per capita emission, including LULUCF, was around -2.96 $\mathrm{GgCo}_{2 \mathrm{e}} / 1$ billion USD. However, in 2013 it reached $0.89 \mathrm{GgCO}_{2 \mathrm{e}} / 1 \mathrm{billion}$ USD (UNFCCC 2017). Besides this, as carbon dioxide and methane are the primary greenhouse gases emitted through human activities in Ethiopia, population growth has a negative impact on $\mathrm{CO}_{2}$ emissions. Hence the population of the country had been growing at $2.53 \%$ on average from 1990-2013. And in 1990 the carbon dioxide per capita emission, including LULUCF, was around $-0.61 \mathrm{GgCo} 2 \mathrm{e} / \mathrm{thousands}$ of populations. However, in 2013 it reached $0.42 \mathrm{GgCo} e /$ thousands of populations (UNFCCC 2017).

\section{Nitrous Oxide}

The other major greenhouse gas emission is nitrous oxide. Nitrous oxide emission is largely caused by anthropogenic factors; the combustion of fossil fuels, industrial processes, transport sectors, land-use change and clearing of the forest, agricultural activities like use of fertilizer, manure or animal wastes are the major anthropogenic source of nitrous oxide (IPCC, 2001; Olivier and Janssens 2012). From

\section{Trends of $\mathrm{CO}_{2}$ Emission Excluding LULUCF (1990-2013)}

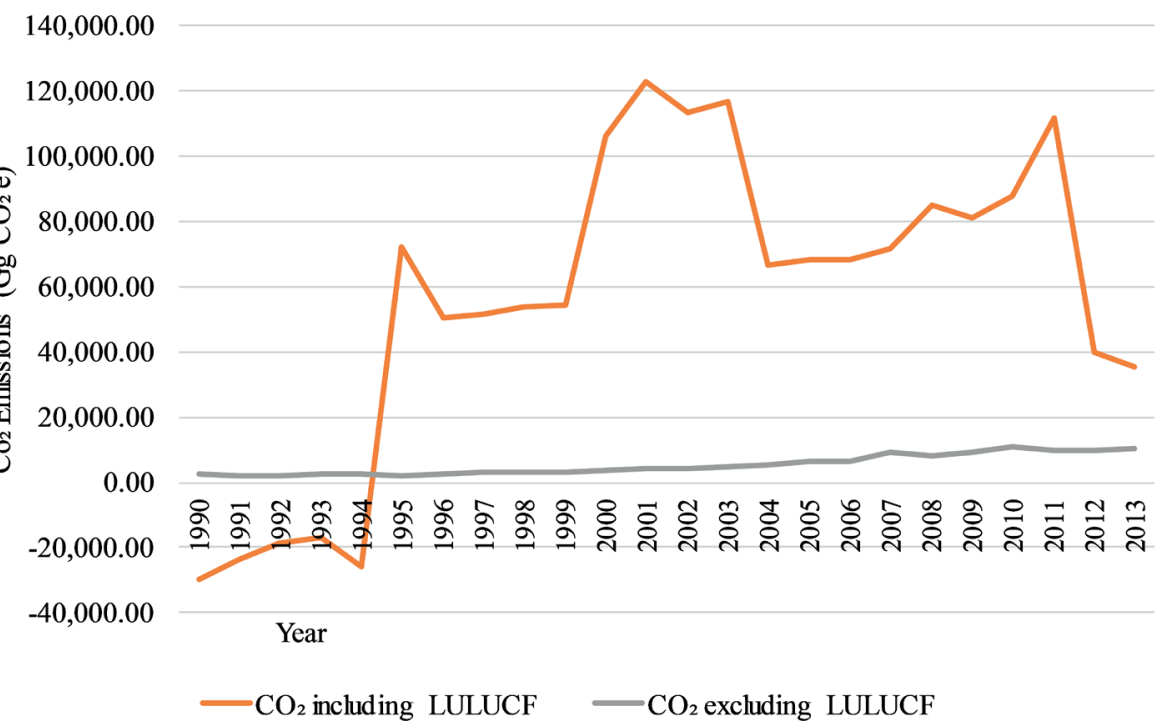

Fig. 2. Computed from UNFCCC Data Interface 
1980-1998 the atmospheric emission of $\mathrm{N}_{2} \mathrm{O}$ continues to increase at a rate of $0.25 \%$ per year. Despite it has shown a reduction at around 50\% from 1991-1993, the emission of $\mathrm{N}_{2} \mathrm{O}$ after 1993 was at rates closer to those observed during the 1980s (IPCC 2001). The amount of nitrous oxide emission in Sub Saharan Africa is attributable to agricultural activities and land-use change and forestry.

Ethiopia has economies dominated by the agricultural sector. As a result of this, nitrous oxide emissions emanating from nitrogenous fertilizer and other agricultural activities become evident. The application of nitrogenous fertilizer and other agricultural activities have contributed to 356,000tcoe nitrous oxide emissions in 2001/02 in Ethiopia. The average agricultural land on which fertilizers applied was $17.012 \mathrm{~kg} / \mathrm{ha}$ in 2002. The level of nitrous oxide emission in Ethiopia have shown increases from 1990-1994 (3,410G cco $_{2 \mathrm{e}}-12134.98$ $\mathrm{GgCO}_{2 \mathrm{e}}$ ). However, in 1995 it decreases from $12134.98 \mathrm{GgCO}_{2 \mathrm{e}}$ to $11025.4 \mathrm{GgCO}_{2}$ with a growth rate of $-9.14 \%$. The rise of the emission has reached $21,952.74 \mathrm{GgCO}_{2 \mathrm{e}}$ in 2008 . Five years lat$\mathrm{er}$, the emissions of nitrous oxide become $24,123.86 \mathrm{GgCO}_{2}$. The level of nitrous oxide emission with and without LULUCF had a slight difference only in 1990 as nitrous oxide with and without LULUCF was around $3410 \mathrm{GgCO}_{2 e}$ and $3100 \mathrm{GgCO}_{2 \mathrm{e}}$. Respectively however, for the rest of the years, it had similar emission values. It is for this reason that the paper has only displayed $\mathrm{N}_{2} \mathrm{O}$ excluding LULUCF in figure 3. The average growth rate of nitrous oxides emission from 1990-2001 was approximately $21.97 \%$. However, it had shown a drastic downward shift from 2002-2013 with an average growth of $8.07 \%$ (Fig. 3). Moreover, according to FDREMoEF, (2015), manure management has contributed the largest share of $\mathrm{N}_{2} \mathrm{O}$ emissions with $45 \%$ of the contribution. It is followed by soil management with $40 \%$ of $\mathrm{N}_{2} \mathrm{O}$ emissions. The rest of $\mathrm{N}_{2} \mathrm{O}$ emission has been contributed by fuel combustion activities, other energy sectors, and wastewater treatment and discharge with 5\%, 5\%, and 4\% respectively. Despite the consumption of fertilizer fluctuating considerably, the average kilogram of fertilizer applied to agricultural land in the same period was around $16.5 \mathrm{Kg} / \mathrm{ha}$ (FDREMoEF 2015). From 2002-2007 the average kilograms of fertilizers applied in agricultural land were $11.85 \mathrm{Kg} / \mathrm{ha}$. From 2008-2013 an average of $21.13 \mathrm{Kg} / \mathrm{ha}$ of fertilizers were applied. Besides this, FAO (as cited in FDREMoEF 2015) has also estimated that 141,000 ha of forest has been lost annually between 1990 and 2010 and that the average annual deforestation rate, based on the change in forest cover from 2005 to 2010, was estimated to be 1.1 percent of total forest cover.

\section{Methane}

Methane is the third but important greenhouse gas that has a contributory effect on greenhouse emissions. Since the period of the industrial revolution, the atmospheric methane emission has been doubled and contributed to more than 20\% of the greenhouse gas effect. Methane is produced through the natural process by bacteria and anthropogenic factors like mining, burning of fossil fuels, and livestock husbandry. Livestock production is the main source of methane emission in developing nations. It has two primary sources of emission; enteric fermentation and manure management. In enteric fermentation, methane emitted when cattle eat plants and ferment it in their stomach and exhale methane. The second source of methane is manure management. In manure management, methane is emitted when cattle excrete manures containing methane. The total emission of methane from enteric fermentation in Ethiopia is very high, which accounts for $40.55 \mathrm{Mt} \mathrm{CO} \mathrm{CO}_{2} /$ year, as compared with other east African countries. For example, Kenya, Tanzania, and Uganda have 11.55, 13.46, and 5.64 $\mathrm{mtCO}_{2} /$ year of methane respectively which is very low as compared with Ethiopia. The total methane emission from manure management is also around $1.41 \mathrm{Mtco}_{2} /$ year, which is very high as compared with the other East African countries' practices (Brown et al. 2012).

The total methane emissions with and without LULUCF have very little difference from 1990-1993. The average methane emission with LULUCF was 37,826.25 Gg$\mathrm{CO}_{2 \mathrm{e}}$ and the average methane emission without LULUCF was 37,500.75 $\mathrm{GgCO}_{2}$ from 1990-1993. However, from 1993-2013 both LULÜCF included and excluded methane emission was similar. The total methane emission, including LULUCF, in Ethiopia, was around 37,821 $\mathrm{GgCO}_{2}$ in 1990. The emission of methane has slight progression and retroversion from year to year until 1996. However, after 1996, as graph4 vividly showed there is a continuous upsurge. As graph4 depicted well, the emission of methane including LULUCF reached 60,729.02 Ggco2e in 2013. The growth rate of methane emission from 1990-1994 was around -4.50\%. From 1995-1999 the average annual emission growth rate of methane was raised by $11.39 \%$. However, from 2000-2004 the average annual emission growth rate of methane was around 2.52\%. From 2005-2009, the average annual emission growth rate of methane was $0.14 \%$, and it turns out to be $2.5 \%$ from 2010-2013. Generally, the emissions of methane increase on average by $2.71 \%$ per annum from 19902013 (Fig. 4). As Ethiopia has the largest livestock population

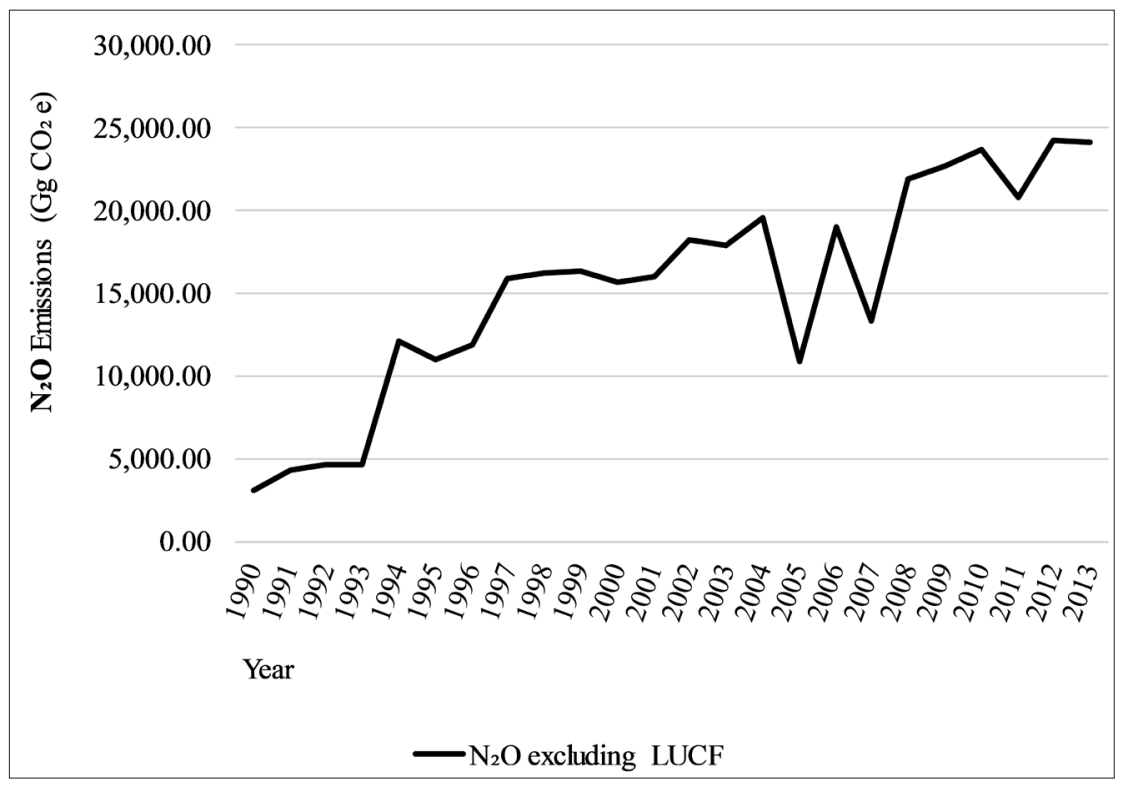

Fig. 3. Trends of $\mathrm{N}_{2} \mathrm{O}$ emission excluding LUCF (1990-2013) 
in Africa consisting of cattle (53 million), sheep (26 million), goats (23 million) and birds (50 million), emission from enteric fermentation, which was associated with domestic livestock, has contributed to the largest $\mathrm{CH}_{4}$ emissions accounting for $26 \%$ of the emissions. Other energy sectors, which primarily come from the use of fuelwood and wood waste in the residential and commercial institutions, have also contributed to $26 \%$ of the emission, and solid waste disposal and decomposition have contributed to $25 \%$. The reset of methane emission comes from wastewater treatment and discharge (6\%), manure management (5\%), biomass burning $(5 \%)$, rice cultivation (3\%), transport (2\%), solid fuels or coal (1\%) and energy industries (1\%) (FDREMoEF 2015). Generally, the agriculture sector contributed the most methane emissions, constituting 53\% of all national methane emissions in 2013.

\section{Sectorial Contributions of Greenhouse Gas Emissions in Ethiopia Agriculture}

Agriculture covers the lion share of the gross domestic product of many developing nations. It has also provided employment opportunities for the vast majority of the population in Sub Saharan countries. However, this sector of the economy produces a large share of greenhouse gas emissions next to land-use change and forestry. The biggest sources of emission in this sector are the encroachment of pasture and cropland into forested areas; livestock manure and digestive processes; burning of Savannah; and cropland management and cultivation practices (Brown et al. 2012).

The greenhouse gas emissions from agricultural practice are basically in the form of nitrous oxide resulting from the application of fertilizer and/or manure in a form of methane resulted from livestock emission and animal manure or rice cultivation. Therefore, agriculture is the main source of nitrous oxide and methane emission. In Ethiopia, agriculture has contributed to the vast majority of greenhouse gas emissions. It has contributed around $35856.67 \mathrm{GgCO}_{2 \mathrm{e}}$ per year from 1990-1994. As compared with 1990, greenhouse gas emission has increased by $1.4 \%$ in 1994. From 1990-1994, the greenhouse gas emission from the agricultural sector has an average growth rate of 0.13\% per annum. From 1995-1999, the average total greenhouse gas emission traced from the agricultural sector reached $38852.47 \mathrm{GgCO}_{2 \mathrm{e}}$ per year. However, unlike the preceding period, this period has shown upward trends of greenhouse gas emissions. The total greenhouse gas emission from this sector increased by $19.26 \%$ from 1995 to 1999 and it had a 3.11\% increase per annum for the respective years. From the year 2000-2004, the total greenhouse gas emission traced from the agricultural sector was averaged around $44216.04 \mathrm{GgCO}_{2 \mathrm{e}}$ per year. It increased by $25.12 \%$ from $2000-2004$. On average the greenhouse gas emission from this sector increased by $6.01 \%$ per annum. From 2005-2009, the agricultural sector has an average greenhouse gas emission of $54773.65 \mathrm{GgCO}_{2 e^{\prime}}$ as compared with the 2005 emissions, the total greenhouse gas emissions in 2009 has increased by 43.28\%. It also had a 9.75\% average annual increase each year. From 2010-2013 the total greenhouse gas emission from this sector increased by $1.65 \%$ as the emission stood at $65438.18 \mathrm{Ggco}_{2 e}$ emissions on average per year. It also had a $1.74 \%$ average annual increase each year during these periods. Generally, from 1990-2013 the total greenhouse gas emission traced from the agricultural sector increased by 3.11\% on average per annum. As it is depicted in Fig.5, agriculture has paramount contributions to the total greenhouse gas emission in Ethiopia (Fig. 6, 7, and 8). The main sources emission in this sector included enteric fermentation (67.48\%), manure management (20.52\%), agricultural soils (8.75\%), and prescribed burning of savannas (3.22\%) and rice cultivation (0.017\%) (UNFCCC 2017).

\section{Land Use and Land Use Change and Forestry (LULUCF)}

Land use and change and forestry is the first leading sector that has contributed to the largest greenhouse gases emission in Ethiopia. This sector contributed to greenhouse gas emissions in changing and modifying the use of landscape. This, perhaps, happens in the form of forest degradations, deforestation, shifting cultivation, wildfire, etc. (MESTI and EPA 2015). Developing countries have shown continuous upward trends of greenhouse gas emissions from the sector. In confirming this fact, Brown et al. (2012) said that from 2001-2006 the native ecosystems underwent a landuse change and about 5.5 million ha/year were converted into cropland in East Africa countries and 1.2 million ha per year in western African countries. Ethiopia also has had the largest native vegetation land converted to cropland from 2001-2006 which is almost 3.6 million hectares. As a result of this, the land use change and forestry is the first largest sector that has contributed to greenhouse emissions. This sector has contributed $43.31 \%$ of greenhouse gas emissions in Ethiopia. From 1990-1994 the total greenhouse gas emanated from land use-land use change and forestry was $-1.03 \%$. However, in between 1995-1999, it grows by

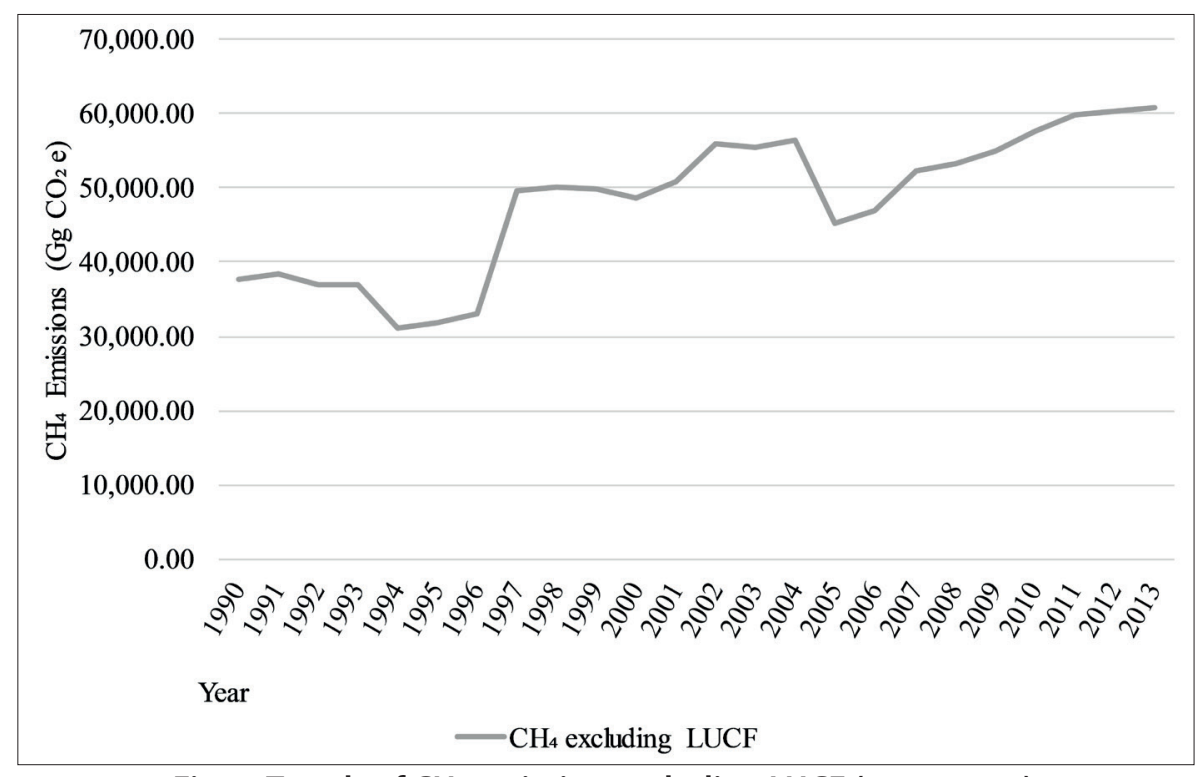

Fig. 4. Trends of $\mathrm{CH}_{4}$ emission excluding LUCF (1990-2013) 
$64.52 \%$. The trends of greenhouse gas emissions from this sector have shown a $12.96 \%$ of growth from 2000-2004. After 2004 the greenhouse gas emission from land use change and forestry had slight progress but downturns after 2012. Nevertheless, in 2013, it has still contributed a large share to Ethiopian greenhouse gas emissions. Generally, from 19902013, the average greenhouse gas emission from this sector was around 50739.73 Ggco2e with a 19.76\% average annual emission growth rate (Fig. 5,6,7, and 8).

\section{Energy Sector}

The energy sectors are one of the main anthropogenic factors that have a huge contribution to global increased greenhouse gas emissions. The energy sector discharges greenhouse gas emissions by burning or combustion of fossil fuels, combustion of biomass and electricity generation. This sector has been a colossal factor for carbon emission in the world, particularly in developed nations. Schreuder (2009) argued that $\mathrm{CO}_{2}$ emissions from fossil fuel burning and industrial processes have been accelerating at a global level with the growth rate of increase from 1.1\% per year (from 1990-1999) to 3\% per year from 2000-2004. The increasing pattern of fossil fuel emission has become exponential; for example, China and India have shown the highest carbon emissions with $67 \%$ and $88 \%$ increase respectively and Japan, the US, and Europe have respectively shown carbon emission increments by $23 \%, 19 \%$, and $6 \%$ (IEA 2012).

Developing countries have comparatively less carbon emissions than developed countries. It is because of this, the Kyoto Protocol leveled developing nations as a non-annex I country. However, their carbon emission is increasing from year to year. Biomass energy or the burning of wood-fuel has contributed to increased carbon emission in Sub-Saharan African countries. It was estimated that 658 million tons of wood-fuel were directly consumed by households and used to produce charcoal in 2012, which led to high carbon emission. However, on the other hand, electricity generation accounted for approximately 63 million tons of $\mathrm{CO}_{2 e}$ and that it shared $2 \%$ of the region's greenhouse gas emissions (Hogarth et al. 2015).

In Ethiopia, the total greenhouse gas emission from the energy sector has grown on average by $9.45 \%$ per year from 1990-2013. This sector is the third-largest sector that has contributed to greenhouse gas emissions in Ethiopia. The emissions from the energy sector were around 6274Gg$\mathrm{CO}_{2 \mathrm{e}}$ in the $1990 \mathrm{~s}$ and reached $17670.12 \mathrm{GgCO}_{2 \mathrm{e}^{\prime}}$ which has increased by $217.99 \%$. Even though Ethiopia did not produce energy from the combustion of fossil fuel it produces electricity from hydropower, which is clean from carbon emissions, but the other sectors (fuel combustion/ biomass energy) and transport sectors have the largest share of emissions in the energy sector as they have 3,918.2 $\mathrm{GgCO}_{2 \mathrm{e}}$ $12,881.3 \mathrm{GgCO}_{2}$ in 2013 . Other sectors (fuel combustion or biomass burning) cover $77.56 \%$ of the energy sector emissions whereas the transport sector has shared $14.67 \%$ of the energy sector emissions. The manufacturing industries and construction cover $5.6 \%$ of the energy sector emission (UNFCCC 2017). What makes this sector different from other sectors is that it has shown progressive increments from year to year. It had a 9.45\% annual average growth rate from 1990-2013 (Fig. 5). This means the sector would be a vanguard greenhouse gas emission sector in the future.

\section{Waste Sector}

Greenhouse gas emissions from this sector include disposal of liquid and municipal solid waste through landfilling, composting, incineration, open burning, and treat- ment of domestic and industrial liquid wastes. The gaseous emissions from this sector are predominantly $\mathrm{CH}_{4}$ and $\mathrm{N}_{2} \mathrm{O}$. However, solid and liquid waste disposals are the dominant factors in the waste sector greenhouse gas emissions (MESTI and EPA 2015).

In Ethiopia, the waste sector has a limited share of the national total greenhouse gas emissions. As clearly shown in Fig. 5, the waste sector has contributed to a total of 3081.21 $\mathrm{GgCO}_{22}$ emissions per year on average ranging from 19902013. This figure seems insignificant but the sector has an average emission growth rate of $7.4 \%$ per annum. Different studies have also confirmed that this sector is one of the dreadful challenges of urban areas in Ethiopia that it would probably have sustainable greenhouse gas emissions. The growth rate of greenhouse gas emission in the waste sector increases by 390.38\% in 2013 as compared with the 1990's waste sector emissions (Fig. 5, 6, 7, and 8). Wastewater handling, solid waste disposal on land, and waste incineration are the dominant subsectors that have contributed to greenhouse gas emissions in the waste sector with a share of 29.06\%, 68.99\%and $1.95 \%$ respectively (UNFCCC 2017).

\section{Industrial Processes and Product Use}

This sector is very different from other sectors because it has adverse and spillover effects. It means that it could have effects not only at the source point but also far away from the source point. This means emissions at a point will have adverse effects at other points. In this sector, emissions are produced as a byproduct of the industrial process. Different kinds of industrial processes can lead to greenhouse gas emissions like mineral industrial sector (cement production, lime production, ceramics, soda ashes), chemical industries, metal industries (iron and steel production, aluminum production), and electronic industries (IEA 2012; IPCC 2006).

In Ethiopia, the industrial sector has still a trivial contribution to the nation's total greenhouse gas emissions as it has a total of $881.21 \mathrm{GgCO}_{2 \mathrm{e}}$ emissions on average from 1990-2013. Despite its triviality, the sector has an average emission growth rate of $20.05 \%$ per year, which is very high as compared with other sectors. From 1990-1994 the sector had an average greenhouse gas emission of $208.89 \mathrm{GgCO}_{2 \mathrm{e}}$. From 1995-1999, it had an average greenhouse gas emission of $323.03 \mathrm{GgCO}_{2 e}$. From 2000-2004 the sector had an average greenhouse gas emission of $643.49 \mathrm{GgCO}_{2 e}$. From 2005-2009, it had an average greenhouse gas emission of 1,732.36 $\mathrm{GgCO}_{2}$ and finally, from 2010-2013, the industrial sector had an average greenhouse gas emission of 1,652.52 $\mathrm{GgCO}_{2}$. These periods have clearly shown that greenhouse gas emissions in the sector are upturning from year to year with increasing growth rates as shown in figure 5 . Among the most subsectors that have contributed to greenhouse gas emission, metal production (48\%) and cement production $(51 \%)$ are the dominant subsectors. Other subsectors like lime, soda ash, and glass production have a trivial contribution to the industrial processes and product use emission (FDREMoEF 2015).

\section{Bunkers Fuel Sector}

Bunker fuels include fuels used for international aviation and maritime transport. This sector is nowadays increasingly influencing the global greenhouse gas emissions. Its trend has increased from time to time. Bunkers fuel had contributed to global greenhouse gas emission with 362.5 $\mathrm{mtCO}_{2 e}$ from maritime transport and $255.3 \mathrm{mtCO}_{2 e}$ from aviation industries and the figure upturned constantly as it reached $488.8 \mathrm{mtco}_{2 \mathrm{e}}$ from the maritime transport and 350 $\mathrm{mtcO}_{2 \mathrm{e}}$ from aviation in 2000 and reached $565.8 \mathrm{mtco}_{2 \mathrm{e}}$ for maritime and $413.8 \mathrm{mtCO}_{2 \mathrm{e}}$ for aviation fuel combustions. In 
2005 and 2010 the greenhouse gas emission from maritime transport and aviation reached $643.7 \mathrm{mtco} 2 \mathrm{e}$ and $455.3 \mathrm{mt}-$ $\mathrm{CO}_{2 \mathrm{e}}$ respectively (IEA 2012).

${ }^{2 \mathrm{e}}$ The bunker fuel, like the waste and industrial sector, has trivial shares of the total greenhouse gas emissions in Ethiopia. All the emissions in this sector are attributable to the aviation industry. This sector has an average growth rate of 57.53\% per year from 1990-2013 with an average emission of $458.65 \mathrm{GgCO}_{2 e}$. From the year 1990-2000, the sector had an average greenhouse gas emission of $210.68 \mathrm{GgCO}_{2 \mathrm{e}}$. From the year 2000-2013, the bunker sector had an average greenhouse gas emission of $649.4 \mathrm{GgCO}_{2 \mathrm{e}}$ (Fig. 5,6,7 and 8).
International Policy Instruments and Measures of Greenhouse Gas Emissions

The United Nations convened a conference in 1972 at Stockholm to deal with environmental problems, which was epitomized by a series of preceding environmental incidents like the trail smelter, Corfu channel, Torrey cannon or black tides. Although there were bilateral and unilateral efforts, before the Stockholm conferences, the international community had no global policy instruments to deal with the environmental problem (Kiss and Shelton 2007). The conference for the first time soaked up global efforts to address environmental problems hinting that environmental problems have global dimensions. The Stockholm conference brought up the Stockholm declaration and UNEP.

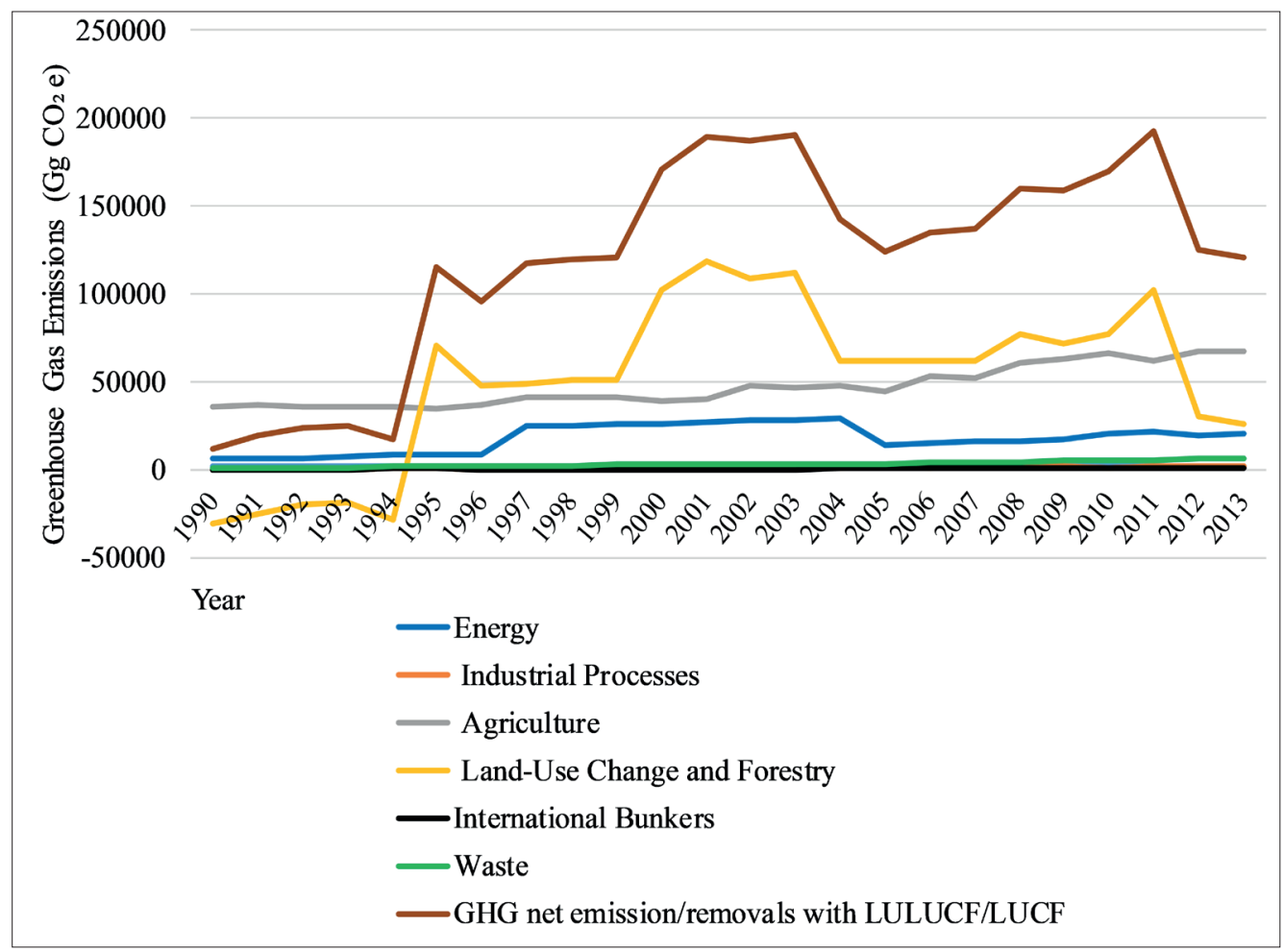

Fig. 5. Trends of greenhouse gas emission in terms of sectors (1990-2013)

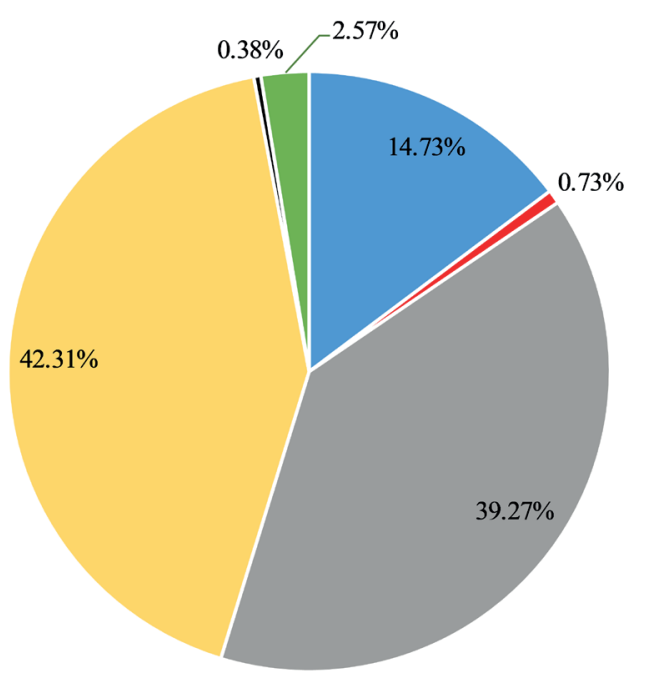

- Energy

- Agriculture

- International Bunkers
- Industrial Processes

Land-Use Change and Forestry

Waste

Fig. 6. Average greenhouse gas emission in terms of sectors (1990-2013) 


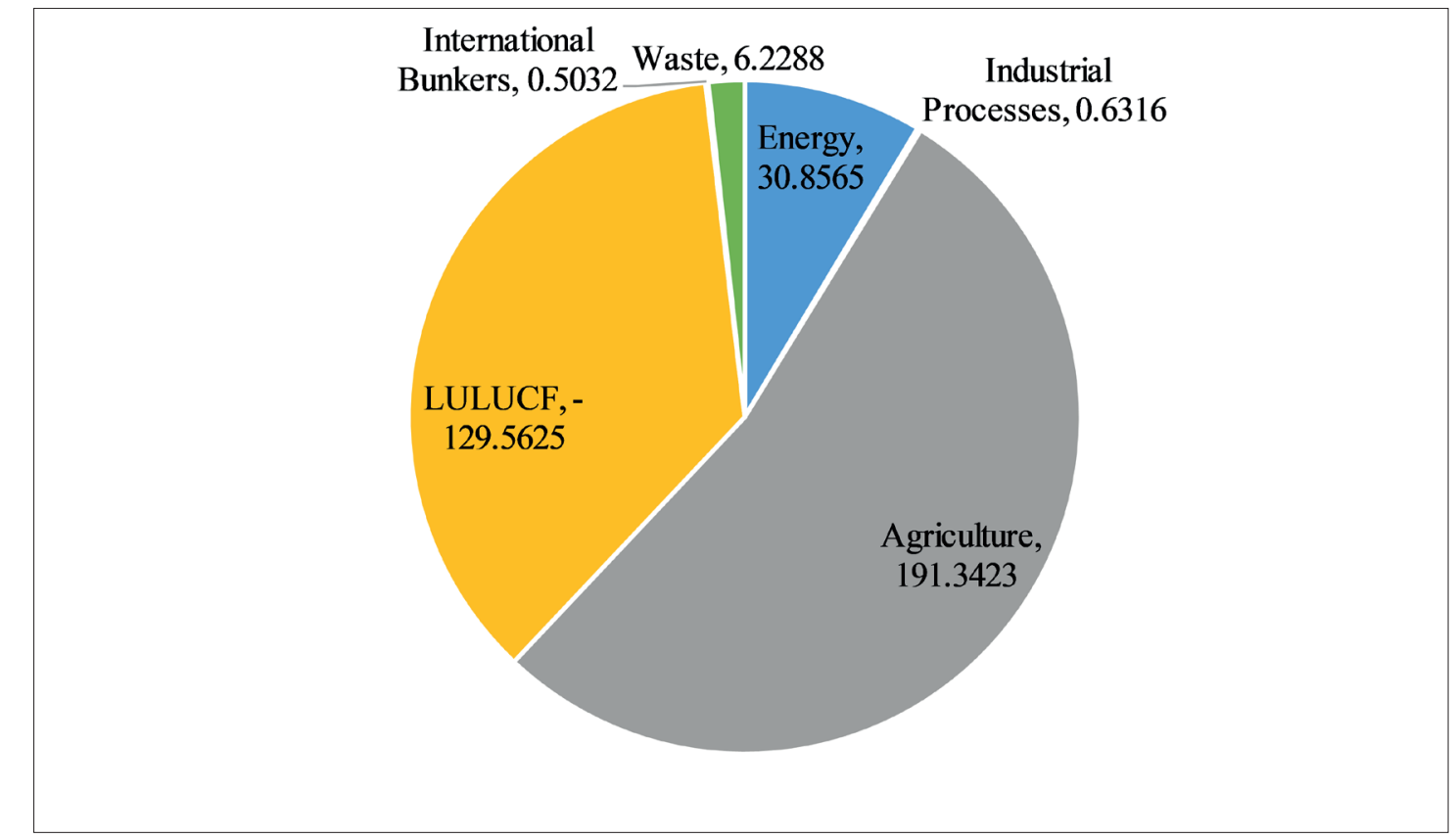

Fig. 7. Sectorial greenhouse gas emission in 1990 (percentage proportional to 1990 total greenhouse gas emission)

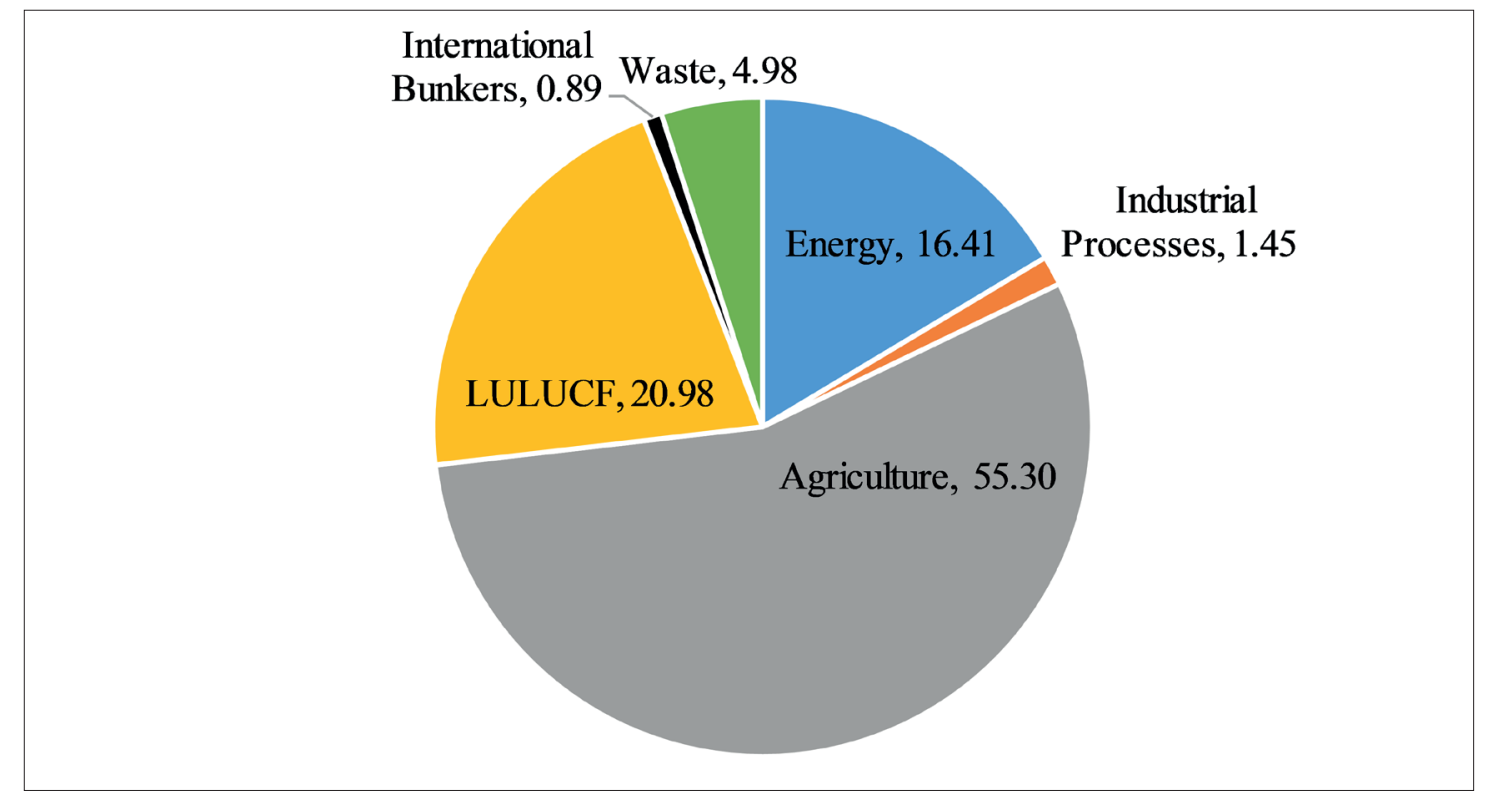

Fig. 8. Sectorial greenhouse gas emission in 2013 (percentage proportional to 2013 total greenhouse gas emission)

The Stockholm declaration recognized man as a primary agent in creating and molding his environment. So, anthropogenic factors are the primary causes of environmental problems. The declaration in article 6 of the principles intended to address toxic pollutants and pollution which are directly or indirectly related to greenhouse gas emissions reduction.

The discharge of toxic substances or of other substances and the release of heat, in such quantities or concentrations as to exceed the capacity of the environment to render them harmless, must be halted in order to ensure that serious or irreversible damage is not inflicted upon ecosystems. The just struggle of the peoples of ill countries against pollution should be supported (UN 1972).

UNEP is another international instrument, which is devised as one of the specialized agencies of the UN, in the Stockholm conference (Kraft 2007). This instrument was considered a forum for discussing environmental problems, influencing environmental policy and assessing the social and economic impacts of climatic change (Cohen and Waddell 2009). Consequently, UNEP in collaboration with the world environment center (WEC) has identified 700 voluntary projects to cut greenhouse gas emissions. It was also successful as it has achieved 1.3 billion tons of cozequevalent reduction (Calhoun 2005).

The international community convened a conference in Austria in 1985. The conference instigated the development of global policies to address climate change and initiated the establishment of the intergovernmental organization that could assess the impact of climatic change. In 1988, in Toronto, Canada, the world conference on changing climate was held with the focus of developing policies and providing solutions to the challenges of climatic change. The conference called on the world to reduce greenhouse gas emissions by 20\% from 1988-2005 and the creation of a global climate convention. The UNEP in collaboration with WMO created the intergovernmental panel on climate change (IPCC) in 1988. IPCC is initiated with the objectives of preparing comprehensive review and recommendations concerning climate change, the social and economic impact of climate change and possible responses to strategies (Sebastian 1999). 
The other notable international policy instrument was the Rio Conference held in 1992. The conference adopted a treaty called the United Nations Framework Convention on Climatic Change. The UNFCCC is initiated to stabilize the greenhouse gas concentrations in the atmosphere. The convention created a forum for discussion on the major global initiatives on reducing greenhouse gas emissions (UNFCCC 2006). Five years later, the major but ill successful conference was held in Kyoto, Japan. The Kyoto Protocol has brought some quantitative measures on the reduction of greenhouse gas emissions. The protocol categorized the world countries into annex I countries (developed countries) and non-annex I countries (developing countries). It also recognized that developed nations were responsible for the majority of greenhouse gas emissions over the last centuries. As a result of this, the protocol tried to levy different responsibilities in developed and developing countries. Developed countries were subjected to emission reduction targets ranging from -8\% to 10\% of the 1990s emission. On the other hand, developing countries were advised to engage in the clean development process (Sebastian 1999).

The Kyoto protocol has introduced very flexible mechanisms for countries to follow to reach emission reduction targets. Different mechanisms of greenhouse gas emission reductions have been introduced as a result of the protocol. Joint Implementation, Emission Trading, and Clean Development are the basic mechanisms that are introduced in the Kyoto Protocol (Schreuder 2009).

Joint Implementation Mechanisms are «defined in Article 6 of the Kyoto Protocol, allows a country with an emission reduction or limitation commitment under the Kyoto Protocol (Annex I Party) to earn emission reduction units (ERUs) from an emission-reduction or emission removal project in another Annex I Party». Joint Implementation Mechanisms offer Parties a flexible and cost-efficient means of fulfilling a part of their Kyoto commitments (UNFCCC 2014). Joint Implementation mechanisms encourage carbon sink byways of planting the forest, cropland management, and re-vegetation. It can be implemented just among the developed nations (Schreuder 2009).

Emission Trading is another strategy used to reduce greenhouse gas emissions. It is a very flexible and market-based approach that is implemented among Annex I countries whereby countries can sell and buy emission units from countries which have positive carbon signs. such a mechanism has tried to provide economic incentives to countries that have reduced greenhouse gas emissions.

Clean Development Mechanisms (CDM) is another strategy used to reduce GHG. It is defined in Article 12 of the Kyoto Protocol that «Annex I Parties can undertake emissions-reduction projects in developing countries (Non-Annex I), which lead to Certified Emission Reduction Credits. These credits can be used for compliance in the industrialized countries» (Schreuder 2009). This indicated that developed countries have the opportunity to engage in investments like greenhouse gas emission reduction projects in developing nations and can earn sellable certified emission reduction units.

Ethiopia as a developing country has to participate in CDM projects so as to reduce poverty by protecting the environment. After 2009, Ethiopia has registered in eight projects under CDM. Among these, three projects are CDM projects and the rest are POAs (a program of activities). The CDM projects are reforestation (Humbo Assisted natural regeneration project, located in southwest Ethiopia), Landfill gas (Repi Landfill Gas Projects in Addis
Ababa), and Methane Avoidance or wastewater (a tannery hub, construction of common effluent treatment plant for industrial waste in Modjo). Apart from this, Ethiopia has already registered five POAs (a program of activities) and four of them are related to the deployment of energy-efficient cook stoves for domestic use and one POA is related to Solar Programme (Ritika et al. 2017).

According to Mohammed (2011), the Humbo Assisted Natural Resource Project can be referred to as one of the success stories of CDM projects. Its achievement stems from the involvement of the local community to rehabilitate the degraded forest area, commitment of the stakeholders to entwine resources and technical capacity, and good institutional support from the Ethiopian Environmental Protection Authority. Hence, it rehabilitated the ecological system and enhanced the economic opportunities of the local community. The second CDM project, Repi CDM Project, is launched in Addis Ababa with the objective of capturing and flaring methane from solid wastes, which is found in Addis Ababa City Administration, Koshe. This project has given a great opportunity to Addis Ababa city administration as it unleashes better waste management practices by recycling it to produce electricity out it. The third CDM project is Methane Avoidance or wastewater (a tannery hub, construction of a common effluent treatment plant for industrial waste in Modjo town), this project appears to be an important opportunity to set up an environmentally friendly leather tanning cluster driven by a network of tanneries in the town and from or around Addis Ababa. The cluster gives priority to common effluent treatment plants to reduce the environmental impact of leather processing (Sandro and Ivan 2017). However, there are some cross-cutting restraint factors to CDM projects, which are relevant to the Ethiopian case. These factors are limitations in national CDM capacities, CDM system complexity, unfavorable national investment climate, smaller overall mitigation potential (represented by national GHG emission levels) and limited prior CDM experience (Ritika et al. 2017).

Generally, the Kyoto protocol was considered less successful because major greenhouse gas emission contributing countries like the US were failed to ratify the protocol (Obaidullah et al. 2016), and emerging economies, like China, India, and Brazil, which are contributing the highest greenhouse gas emissions were not induced with carbon caps as the protocol treated them in non-annex I countries. Nevertheless, EU countries had successful records in implementing the Kyoto protocol nations (Schreuder 2009). After the Kyoto protocol, series of negotiations and conferences were held in Marrakesh Accords (COP 7) in 2001, Copenhagen Accord (COP 15) in 2009, and the Paris Agreement (COP 21) in 2015.

The Paris Agreement can be considered as a concerted global response to climate change challenges. The goal is to keep the world temperature below a 2-degree Celsius increase as compared to the pre-industrial period. It has also aimed at strengthening the capacity of member states to deal with the impact of climate change. Hence, appropriate financial adaptations, technology transfer, mitigation or capacity-building frameworks have been used as instrumental tools to deal with climate change. This agreement has appreciated the differences in capacities among developing countries to deal with climate change. It is for this reason that the Paris Agreement creates a strong link between support and the degree of efficacy and commitments of the actions of developing countries. The Agreement acknowledges the need for support in order to enforce the agreement effectively and allows for a greater 
commitment in the actions of developing countries; and enhances the effectiveness of adaptation planning (Pauw et al., 2019).

Nationally Determined Contributions (NDCs) have been crucial to achieving the Paris Agreement's adoption in 2015 and instrumental in its implementation over the coming decades. There are three key features of these climate action plans. First, NDCs are universal: the NDC has been submitted by nearly every party to the United Nations Framework Convention on Climate Change (UNFCCC). Second, NDCs provide considerable flexibility for countries to adjust their goals to national circumstances and priorities. Third, the Paris Agreement creates five-year review and update cycles designed to make NDCs more ambitious over time (Pauw et al., 2019).

However, like the preceding protocol, Kyoto Protocol, the US, the leading $\mathrm{CO}_{2}$ emitter, Obaidullah et al (2016), has decided to withdraw from the Paris Agreement. This shows that there was no global consensus on actions directed toward the reductions of greenhouse gases. Lack of effective compliance mechanisms can be counted as a reason for the failures (Jonathan et al., 2018).

\section{Policy Instruments and Measures of Greenhouse Gas Emissions in Ethiopia}

Ethiopia as a developing nation has not subjected to carbon reduction quota or limitation. Rather it has to gear its efforts toward clean development mechanisms. The country, in doing so, has introduced environmental policies. There have been different laws, proclamations, directives, policies, and strategies that deal with environmental issues. The environmental policy that was introduced in 1997 by the council of ministers, intended to ensure sustainable development by protecting the environment. In 2010, environmental impact assessment has been issued in «Proclamation 299/2002 E.C.» This environmental policy, let alone how successful it is, has obliged every development project and program to execute impact assessments on the environment and ensure sustainable development. Parallel to this, the country has introduced environmental pollution control proclamation, "Proclamation 300/2002» in 2010. This proclamation forced development projects to take environmental impact estimates and evaluate the efficiencies and effectiveness of pollution control mechanisms as per the proclamation. In 2015, Proclamation 513/2007 of solid waste management was introduced by the country. The Proclamation was issued as a counter-response to the very deleterious solid wastes and intended to enhance values gained from it. These practices, in turn, have the capacity to decrease greenhouse gas emissions from wastes. The council of ministers has also introduced a very specific pollution control proclamation concerning industries in 2016. It was Proclamation 159/2008 of industrial pollution control. This Proclamation intends to make industrial developments compatible with environmental protection activities and it has issued pollution level limits. Besides, there are different directives like environmental impact assessment directives in 2011, and environmental protection plan directives in 2004 (FDREMoST 2016).

The major environmental policy that can be cited in the country is the 2011 Climate Resilient Green Economy (CRGE). This environmental policy has specifically address climate change and greenhouse gas emissions. The CRGE despite ambitious goals was envisioned to achieve the middle-income status by 2025 while limiting greenhouse gas emissions around $250 \mathrm{Mt} \mathrm{CO}_{2 \mathrm{e}}$. In doing so, the CRGE adopted sectorial approached initiatives and identified and prioritized around 60 initiatives to limit GHG emissions around $250 \mathrm{Mt} \mathrm{CO}$, while achieving its development goals (FDRE 2012). The CRGE is based upon the following principles;

Improving crop and livestock production practices for higher food security and farmer income while reducing emissions, Protecting and re-establishing forests for their economic and ecosystem services, including as carbon stocks, expanding electricity generation from renewable sources of energy for domestic and regional markets, Leapfrogging to modern and energy-efficient technologies in transport, industrial sectors, and buildings (FDRE 2012).

Although attaining such goals needs a total expenditure of USD 150 billion in the next 20 years for GHG abatement costs, the government has selected four sectorial based initiatives: i) exploiting the vast hydropower potential, ii) large-scale promotion of advanced rural cooking stoves, iii) efficiency improvements to the livestock value chain and iv) reducing emissions from deforestation and forest degradation (REDD) (FDRE 2012, 2016).

Agriculture has been and is projected to be responsible for the largest share of Ethiopia's GHG emissions until 2030 (Wang and Mersmann 2019). The total greenhouse gas emission from agriculture which is attributable to livestock was around $65 \mathrm{Mt} \mathrm{CO}_{2}$ in 2010 and with the implementation of Climate Resilient Green Economy (CRGE) it would be around $125 \mathrm{Mt} \mathrm{CO2e} \mathrm{in}$ 2030 and from crops sector, the total greenhouse gas emission was around $19 \mathrm{Mt} \mathrm{CO}$ in 2010 that could be limited to $71 \mathrm{Mt}$ CO2e in 2030. The NDCs report of the country revealed that in $2013,31 \%$ of the agriculture sector's emissions resulted from livestock, 39\% from cropland and 24\% from grassland. The remaining share of emissions includes direct and indirect nitrous oxide emissions from managed soils, biomass burning, urea application, and rice cultivation. In 2030, the share of livestock emissions is projected to rise to $45 \%$ while cropland emissions account for $32 \%$ of the sector's total emissions, and grasslands account for only $11 \%$. The government has action plans like decreasing the number of livestock while increasing livestock productivity and shifting from higher GHG emitting livestock (enteric fermenting animals) to lower GHG emitting livestock (non-enteric fermenting animals) like poultry, increasing land productivity and intensifying irrigations to reduce GHG emissions from the agricultural sector. However, due to the increasing patterns of use of fertilizer, new land conversion to cropland every year, an increasing number of cattle every year, it could be very difficult to limit the greenhouse gas emissions to $71 \mathrm{Mt} \mathrm{CO2e} \mathrm{in}$ 2030 (FDRE 2012).

The other largest greenhouse gas emission sector is land use- land use change and forestry. In this sector, deforestation and forest degradation are the primary contributors to greenhouse gas emissions. The Climate Resilient Green Economy (CRGE) planned to reduce greenhouse gas emissions from this sector by providing efficient stoves, (biogas and electric stoves) to rural societies, afforestation/reforestation and forest management. In doing so, it intended to decrease emissions by $40 \mathrm{Mt} \mathrm{CO}_{2 \mathrm{e}}$ in 2030 from the sector. The Climate Resilient Green Economy (CRGE) has provided targets for each sector with preferable action plans. For example, in the 
energy sector, the policy aimed at generating electric power from hydropower (renewable energy sources) around 28TWh by 2030 and decrease GHG emissions by $20 \mathrm{Mt} \mathrm{CO}$ in 2030 as hydropower generation does not produce greenhouse gases and thus is mostly termed as a green source of energy (Owusu and Asumadu 2016).

In the industry sector, it has been found that the cement industry has about 70\% (5 $\mathrm{Mt} \mathrm{CO}_{2 \mathrm{e}}$ ) abatement potentials. Other industrial sectors (leather, chemical, fertilizer, textile, paper, and pulp) account for $6 \mathrm{Mt} \mathrm{CO}$ abatement potentials in 2030. And other energy-efficient technologies or equipment in the industrial sector have an estimated abatement potential of $6 \mathrm{Mt} \mathrm{CO}_{2 e}$. The use of biomass energy in the industrial sector is also estimated at around $4 \mathrm{Mt} \mathrm{CO}_{2}$ abatements. In the transport sector, the construction of the electric rail network has an estimated $9 \mathrm{Mt} \mathrm{CO}_{2}$ abatement potentials and the introduction of fuel-efficient vehicles will have also an estimated abatement potential of $3 \mathrm{Mt} \mathrm{CO}_{2 \mathrm{e}}$ in 2030 (FDRE 2012). Nevertheless, Ethiopia's NDC has estimated the transport sector to have an abatement potential of $10 \mathrm{MtCO}_{22}$. Transport emissions have been increasing continuously as it was only sector $1.0 \mathrm{MtCO}_{2 \mathrm{e}}$ in 1994, but in 2013 it was responsible for $5.5 \mathrm{Mt} \mathrm{CO}_{2 e}$ emissions. According to the SNC, these emissions are projected to multiply five-fold until 2030, reaching 25.4 $\mathrm{Mt} \mathrm{CO}_{2}$. Ethiopia's NDC puts the transport sector emissions at $40^{\circ}$ Mt CO ${ }_{2 e^{\prime}}$ however, the CRGE and Ethiopia's Climate Resilient Transport Sector Strategy put it at $40.7 \mathrm{Mt} \mathrm{CO}$ in 2030 (Wang and Mersmann 2019). Therefore, the CRGE has ambitious mitigation measures as it has focused on specific policy areas.

Moreover, Ethiopia tries to restrain greenhouse gas emissions by providing financial support for investments in low-carbon cooking and baking devices, providing financial support for small-scale irrigation, establishing financial provisions for farmers for improved inputs and equipment, and supporting setting up a continuing forest data inventory. Therefore, the country has a comprehensive set of climate change mitigation policies and strategies that already cover all relevant sectors for emission mitigation, focusing in particular on agriculture, forestry, transport, power, and waste (Wang and Mersmann 2019).

\section{CONCLUSION}

Although developing countries have comparatively less share of global greenhouse gas emissions, their level of emission is growing from time to time. The agricultural sector and land-use management and forestry change have contributed a lot to their greenhouse gas emissions. Likewise, Ethiopia has a limited share of global and regional greenhouse gas emissions. However, its greenhouse gas emissions are showing upward trends from time to time with little swings in some periods. Although most greenhouse gas emitting sectors are showing increasing trends, the land use-land use change and forestry and agricultural sector have been contributing the huge shares for greenhouse gas emission in the country as both have $50739.73 \mathrm{GgCO}_{2 \mathrm{e}}$ and $47093.63 \mathrm{GgCO}_{2 \mathrm{e}}$ emissions per year on average from 1990-2013 respectively. The energy sectors has also contributed $17670.13 \mathrm{GgCO}_{2 \mathrm{e}}$ per year on average from 1990-2013. However, other sectors, which have a trivial contribution to greenhouse gas emissions, have shown the highest annual growth rate. For example, the industrial sector has an annual average growth rate of $20.05 \%$ of greenhouse gas emissions. The energy and waste sector have also a $9.45 \%$ and $7.4 \%$ average annual growth rate of greenhouse gas emission respectively. This might show the potential of the sectors to dominate the other sectors in greenhouse gas emissions. Nevertheless, Ethiopia has introduced different policies in controlling the level of greenhouse gas emissions. Among them Climate Resilient Green Economy (CRGE), notably intended to limit the level of greenhouse gas emissions around $250 \mathrm{mtcO}_{2 \mathrm{e}}\left(250000 \mathrm{GgCO}_{2 \mathrm{e}}\right)$ by implementing action plans concerning each sector. Therefore, if Ethiopia implemented all detail action plans of CRGE, it would have the capacity to limit greenhouse gas emissions.

\section{REFERENCES}

Brown S., Graiz A., Ambagis S. and Pearson T. (2012). Baseline GHG Emissions from the Agricultural Sector and Mitigation Potential in Countries of East and West Africa. In CGIAR research program on climate change, agriculture and food security (CCAFS) (13). Copenhagen.

CAIT. (2017). CAIT Country Greenhouse Gas Emissions: Sources and Methods. World Resource Institute.

Calhoun Y. (2005). Environmental policy. Philadelphia: Chelsea House.

Cohen S. and Waddell W. (2009). Climate change in the 21st century. Montreal: McGill Queens University Press.

FDRE. (2012). Ethiopia's Green Economy strategy; Climate Resilient Green Economy. Addis Ababa: MoEFCC.

FDRE. (2016). NATIONAL REDD+ STRATEGY. Strategy, DOI: 10.1596/24957.

FDREMoEF. (2015). Ethiopia's Second National Communication to the United Nations Framework Convention on Climate Change (UNFCCC).

Addis Ababa: FDREMoEF.

FDREMoST. (2016). Environment and social management framework. Addis Abab: MoST.

Hogarth A., Haywood C. and Whitley S. (2015). Low-carbon development in Sub-Saharan Africa 20 cross-sector transitions. London. IEA. (2012). CO2 Emissions from Fuel Combustion (III), DOI: 10.1787/co2_fuel-2012-en.

IPCC. (2001). Climate Change 2001: The Scientific Basis. Contribution of Working Group I to the Third Assessment Report of the Intergovernmental Panel on Climate Change (Houghton J., Ding Y., Griggs D., Noguer M., Van der Linden P., Dai X., Maskell K. and Johnson C., Eds.). [online] Available at: www.ipcc.ch/report/ar3/wg1/ [Accessed 20 May 2020].

IPCC. (2006). 2006 IPCC Guidelines for National Greenhouse Gas Inventories (Eggleston S., Buendia L., Miwa K., Ngara T. and Tanabe K., Eds.). Hayama, Japan: Institute for Global Environmental Strategies (IGES).

Jonathan P., Jeffrey S., Tim S. and Sylvia I. (2018). The impact of the US retreat from the Paris Agreement: Kyoto revisited? Climate Policy, 18(7), 818-827, DOI: 10.1080/14693062.2017.1412934.

Kiss A. and Shelton D. (2007). Guide to international environmental law. In Guide to International Environmental Law. Leiden: Nijhoff, DOl:

10.1163/ej.9781571053442.1-329.

Kraft M. (2007). Environmental Policies and Politics. USA: Pearson Education.

MESTI and EPA. (2015). National Greenhouse Gas Inventory Report; Ghana's Submission to UNFCCC. Republic of Ghana: MESTI and EPA. 
Mohammed B. (2011). Opportunities and challenges of carbon trade prodects in promoting sustainable development: the case humbo assisted natural regeneration project. Addis Ababa: Addis Ababa University. [Thesis].

Obaidullah M., Samuel A. and Madina O. (2016). The relationship between carbon dioxide emissions, energy consumption and GDP: A recent evidence from Pakistan. Cogent Engineering, 3(1), DOI: 10.1080/23311916.2016.1210491.

Olivier J. and Janssens M. (2012). Greenhouse-Gas Emissions. Netherlands: Netherlands Environmental Assessment Agency and EDGAR.

Owusu P. and Asumadu S. (2016). A review of renewable energy sources, sustainability issues and climate change mitigation. Cogent Engineering, 3(1,1167990), 14, DOI: 10.1080/23311916.2016.1167990.

Pauw W., Castro P., Pickering J. and Bhasin S. (2019). Conditional nationally determined contributions in the Paris Agreement: foothold for equity or Achilles heel? Climate Policy, DOl: 10.1080/14693062.2019.1635874.

Ritika T., Marie J. and Carsten W. (2017). Germany's carbon market cooperation with Ethiopia: Prospect for engaging with Article of the Paris Agreement. Berlin: DEHSt.

Sandro S. and Ivan K. (2017). Case Study: Leather Industry Parks: Planning, Implementation, Benefits, Challenges and Experiance. Vienna: The United Nations Industrial Development Organization.

Sarkodie S. and Strezov V. (2019). Economic, social and governance adaptation readiness for mitigation of climate change vulnerability: Evidence from 192 countries. Science of the Total Environment, 656(150-164), 15, DOI: 10.1016/j.scitotenv.2018.11.349.

Schreuder Y. (2009). The corporate greenhouse climate change policy in a globalizing world. London.: Zed Books.

Sebastian O. (1999). The Kyoto Protocol - International Climate Policy for the 21st Century. In Alexander C. (Ed.), Ecologic Institute: Science and Policy for a Sustainable World. [online] Available at: www.ecologic.eu/422 [Accessed 20 May 2020].

See M. (2001). Greenhouse gas emissions: Global business aspects. Berlin: Springer.

UN. (1972). Declaration of the United Nations Conference on the Human Environment. Stockholm. United Nations Environment Programme. UNFCCC. (2006). United Nations Framework Convention on Climatic Change Handbook. Germany: Climate Change Secretariat.

UNFCCC. (2014). Joint implementation mechanisms. [online] Available at: www.unfccc.int/kyoto\$_\$protocol/mechanism [Accessed 25 September 2018]. 2020].

UNFCCC. (2017). Greenhouse Gas Inventory Data. [online] Available at: www.di.unfccc.int/detailed_data_by_party. [Accessed 15 January

USAID. (2015). Greenhouse Gas Emissions in Ethiopia. Ethiopia: USAID

Wang H. and Mersmann, F. (2019). Implementation of nationally determined contributions: Ethiopia country report. Dessau-Roßlau: Umweltbundesamt. (in German).

World Bank. (2013). GDP per Capita Growth(\% annual) Ethiopian Data. [online] Available at: www.data.worldbank.org/indicator/NY.GDP. PCAP.KD.ZG? contextual=aggregate\&end=2013\&locations=ET\&start=1990 [Accessed 25 December 2019]. 